\title{
Trends analysis of PM source contributions and chemical tracers in NE Spain during 2004-2014: a multi-exponential approach
}

Marco Pandolfi et al.

Correspondence to: Marco Pandolfi (marco.pandolfi@idaea.csic.es)

The copyright of individual parts of the supplement might differ from the CC-BY 3.0 licence. 


\section{Supporting Information}

1) Effect of the change of the location of the measuring station in BCN in 2009

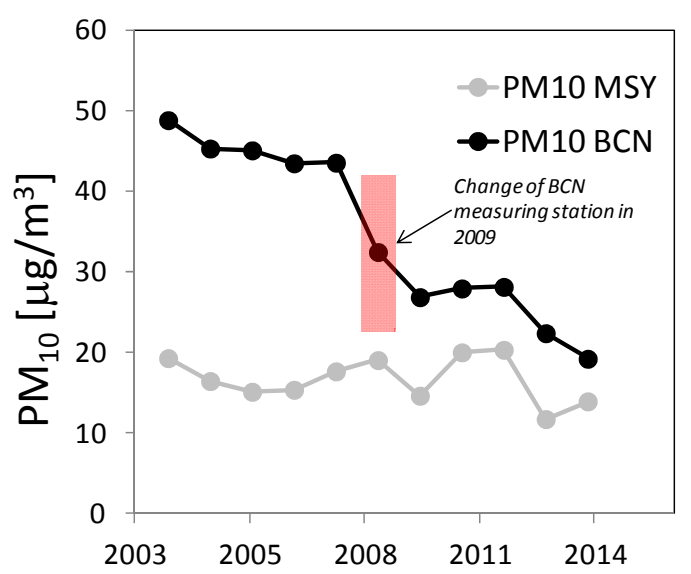

Figure SI-1: Trends of $\mathrm{PM}_{10}$ concentrations from gravimetric measurements at $\mathrm{BCN}$ and MSY. Red rectangle highlights the decrease of $\mathrm{PM}_{10}$ concentration at $\mathrm{BCN}$ due to the change of the location of the $\mathrm{BCN}$ measuring station in 2009. 


\section{2) PMF source profiles at $B C N$ and MSY}
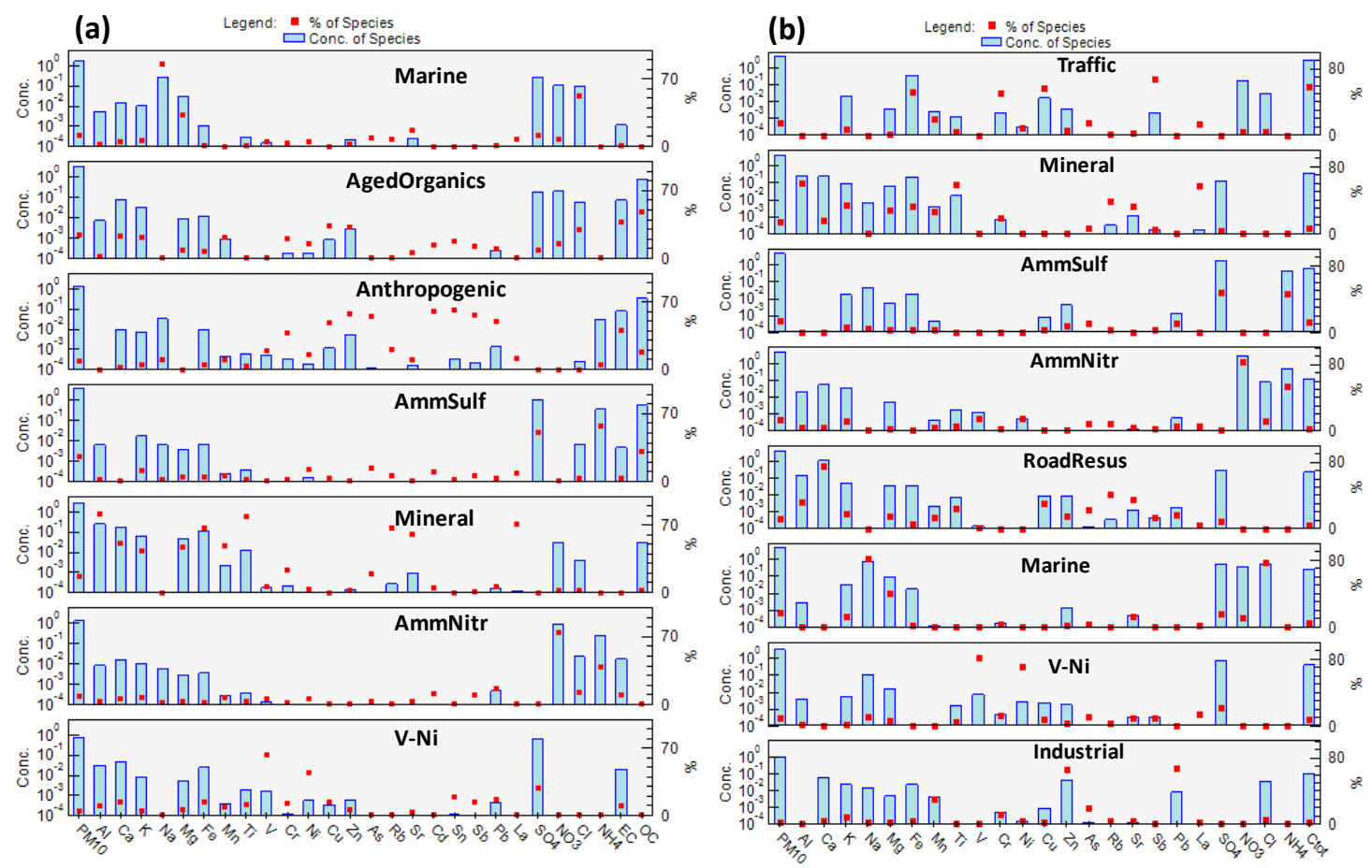

Figure SI-2: Chemical profiles of the PMF sources at MSY (a) and BCN (b)

Source profiles from PMF analysis at BCN and MSY. Common sources at both BCN and MSY were: Secondary Sulfate (secondary inorganic source traced by $\mathrm{SO}_{4}{ }^{2-}, \mathrm{NH}_{4}{ }^{+}$with contribution from $\mathrm{OC}$ ), Secondary nitrate (secondary inorganic source traced by $\mathrm{NO}_{3}{ }^{-}$and $\mathrm{NH}_{4}^{+}$), $\mathrm{V}$-Ni bearing (traced mainly by $\mathrm{V}, \mathrm{Ni}$ and $\mathrm{SO}_{4}{ }^{2-}$ it represents the direct emissions from heavy oil combustion), mineral (traced by typical crustal elements such as $\mathrm{Al}, \mathrm{Ca}, \mathrm{Ti}, \mathrm{Rb}, \mathrm{Sr}$ ), aged marine (traced by $\mathrm{Na}$ and $\mathrm{Cl}$ mainly with contributions from $\mathrm{SO}_{4}{ }^{2-}$ and $\mathrm{NO}_{3}{ }^{-}$). Non common sources at MSY were: Industrial/Traffic source (Anthropogenic source traced by EC, OC, $\mathrm{Cr}, \mathrm{Cu}, \mathrm{Zn}, \mathrm{As}$, $\mathrm{Cd}, \mathrm{Sn}, \mathrm{Sb}$ and $\mathrm{Pb}$ includes contributions from anthropogenic sources such as traffic and metallurgic) and Aged organics (traced by $\mathrm{OC}$ and EC mainly with maxima in summer indicating a biogenic origin). Non common sources at BCN were: Traffic (traced by $\mathrm{Cnm}, \mathrm{Cr}, \mathrm{Cu}$, Sb and Fe mainly and contributing $5.14 \mu \mathrm{g} / \mathrm{m}^{3}(15.1 \%)$ ), Road resuspension (traced by both crustal elements, mainly $\mathrm{Ca}$, and traffic tracers such as $\mathrm{Sb}, \mathrm{Cu}$ and $\mathrm{Sn}$ and contributing $4.25 \mu \mathrm{g} / \mathrm{m}^{3}(12.5 \%)$ ) and Industrial (traced by $\mathrm{Pb}, \mathrm{Cd}$, As and $\mathrm{Zn}$ and contributing $0.96 \mu \mathrm{g} / \mathrm{m}^{3}$ (2.8\%). 


\section{3) OC:EC ratio statistic at Montseny (MSY)}

(a)

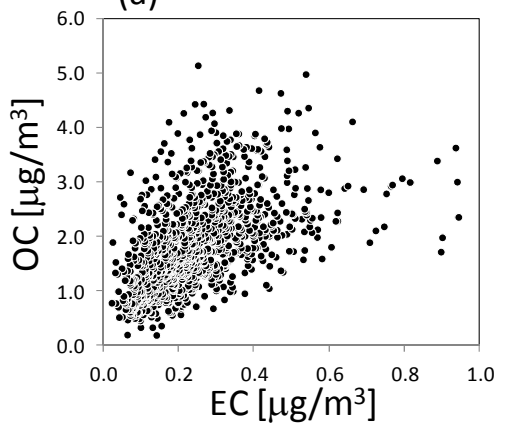

(b)

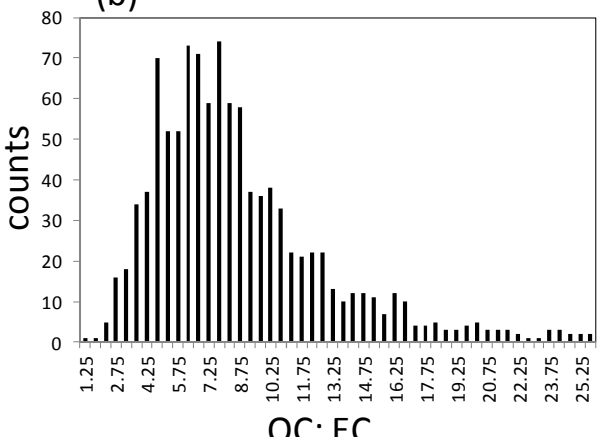

Figure SI-3: OC and EC scatterplot (a) and frequency distribution of the OC:EC ratio (b) at Montseny (MSY) station.

Mean and median values of the OC:EC ratio at MSY were 9.1 and 7.8, respectively.

\section{4) PMF Barcelona: 2007-2014 (with OC and EC) vs. 2004 - 2014 (with Cnm)}
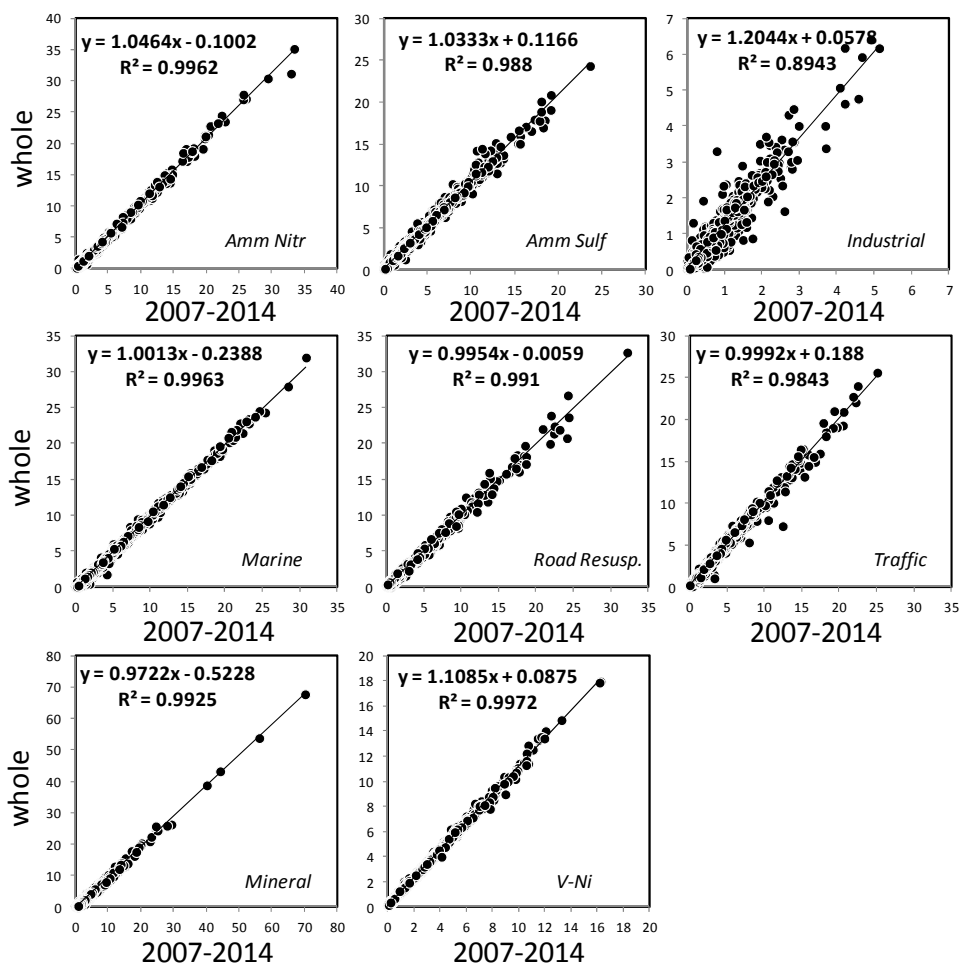

Figure SI-4: Comparison between PMF results at BCN obtained using the period 2007-2014 (separate OC and EC measurements available) and using the whole period 2004-2014 (Cnm was used in PMF). 
5) OC:EC ratio statistic at Barcelona (BCN)
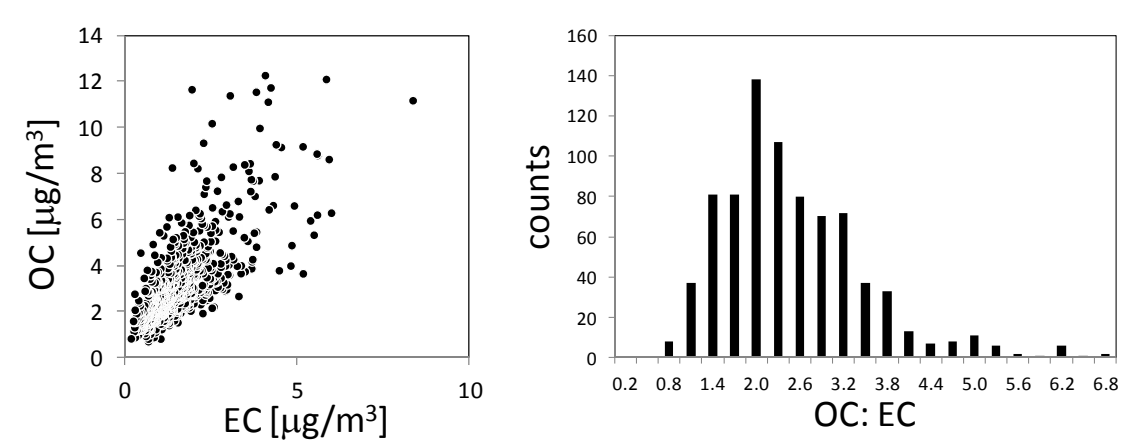

Figure SI-5: OC and EC scatterplot (a) and frequency distribution of the OC:EC ratio (b) at Barcelona (BCN) station. 